\title{
Understanding Who Enrolls in Introductory Computing Courses at Community Colleges
}

\author{
Beth A. Quinn ${ }^{\dagger}$ \\ NCWIT \\ University of Colorado \\ Boulder, CO, USA \\ beth.quinn@colorado.edu
}

\author{
Wendy M. DuBow \\ NCWIT \\ University of Colorado \\ Boulder, CO, USA \\ wendy.dubow@colorado.edu
}

\author{
David Sul \\ Sul \& Associates \\ Petaluma, CA USA \\ dsul@sulandassociates.com
}

\begin{abstract}
Effective teaching requires understanding where students are coming from. Retaining students who have been historically underrepresented in computing requires the same, especially in introductory courses. This paper draws from surveys of students in introductory computing courses at seven geographically dispersed community colleges. We use K-means cluster analysis to differentiate students based on their responses to questions measuring constructs related to student success in computing courses and persistence. The resulting five clusters were compared on outcome variables, including final grades, intent to persist in computing, and gender and race/ethnicity. We focus on community colleges because they are uniquely well-positioned to broaden participation in computing; however, the implications extend beyond the community college context. We conclude by discussing methodological and pedagogical implications, including how findings can challenge assumptions and stereotypes about introductory computing students.
\end{abstract}

\section{KEYWORDS}

introductory courses, cluster analysis, student demographics, broadening participation in computing

\section{ACM Reference format:}

Beth Quinn, Wendy DuBow and David Sul. 2018. Understanding Who Enrolls in Introductory Computing Courses at Community Colleges. In Proceedings of $50^{\text {th }}$ ACM Technical Symposium on Computer Science Education (SIGCSE '19), February 27-Mar. 2, 2019, Minneapolis, MN, USA. ACM, NY, NY, USA, 7 pages. 7 pages. https://doi.org/10.1145/1234567890

\section{Introduction}

In the first two years of college, students often take a variety of classes, as they figure out their interests, fulfill general education requirements, and learn how to navigate the post-secondary environment. As anyone who has taught introductory level courses knows, students end up in introductory classes for a

Permission to make digital or hard copies of all or part of this work for personal or classroom use is granted without fee provided that copies are not made or distributed for profit or commercial advantage and that copies bear this notice and the full citation on the first page. Copyrights for components of this work owned by others than ACM must be honored. Abstracting with credit is permitted. To copy otherwise, or republish, to post on servers or to redistribute to lists, requires prior specific permission and/or a fee. Request permissions from Permissions@acm.org.

SIGCSE '19, February 27-March 2, 2019, Minneapolis, MN, USA

(C) 2019 Association for Computing Machinery.

ACM ISBN 978-1-4503-5890-3/19/02...\$15.00

https://doi.org/10.1145/3287324.3287402 variety of reasons and what they experience in that introductory class can change their academic path. Computer science (CS) education research suggests that a student's experience in the introductory CS classes can be critical points for sparking their interest in CS or turning them off $[16,20,24,25]$. As researchers interested in broadening participation in computing, our goal is to provide recommendations to faculty on how to do effective "inreach" and to implement high-yield retention strategies. To do this, we need to understand the types of students who start in the introductory CS classes. This paper explores whether a clear typology of community college students in introductory CS courses can be determined and if demographic groups are distributed differently across these types.

In the last decade, increasing attention has been paid to the need to broaden participation in computing for reasons of equity and for the benefits that diversity of thought and background can bring to a field based on innovation. At the post-secondary level, some of these efforts have focused on changing introductory CS classes to be more inviting to different kinds of students $[19,23,24]$. Many of these efforts have been successful in attracting more students with diverse backgrounds to the major, particularly at elite colleges [7]. Still, some faculty may make unsupportable assumptions about their introductory students that can have implications for who is encouraged to continue in the field and who is not [9]. While it has been argued that making CS courses more welcoming to historically underrepresented populations makes them better for everyone, we need to know more about how that works.

In this paper, we outline a new approach to understanding differences and similarities among students enrolled in introductory computing courses. Rather than make a priori assumptions about demographic groups, we classify students based on constructs shown to influence success and persistence in computing, including prior programming experience $[1,20]$, interest in computing [26], and assessment of skills and abilities related to success in computing [26]. We compare the resulting clusters of students on key outcome variables, including final grades and intent to persist in computing, and then on demographic classifications, such as gender and race/ethnicity.

This paper reports a preliminary application of this approach on students drawn from CS0 and CS1 courses from seven geographically dispersed community colleges in the United States. We focus on community colleges because of their mission to serve 
students in their local communities, whatever their background. Thus, they are uniquely well-positioned to broaden participation in computing. Because over $70 \%$ of the students in our sample intend to transfer to a 4-year institution, their educational trajectory has implications for 4-year departments. The others could complete their associate's degree or certificate and begin work in industry straight out of community college, so their trajectory affects the workforce more directly.

Data come from a National Science Foundation-funded project that piloted a new professional development program (PD) with community college faculty members from around the country. After faculty chose the course they deemed most pivotal in retaining students in their programs, we surveyed students in each of these "target courses" and interviewed a subset of their students.

\section{Methods}

The overall project included administration of a student survey at two points in time, and interviews with the participating faculty and a subset of students. For this paper, only data from surveys administered to, and interviews conducted with, students enrolled in the fall and spring terms AY 2017-2018 are reported.

Surveys were administered to students in the participating faculty members' target courses (CS0 or CS1) during a lab period early in the term. Students accessed the survey on lab computers via SurveyMonkey, and participation was voluntary. As incentive, students could opt in to a drawing for $\$ 100$.

Within the survey, students could agree to be interviewed, and to date we have completed hour-long interviews with 25 students by videoconference or telephone. The semi-structured interview protocol contained questions about their motivations and expectations for attending a community college, their academic and career intentions, and their perceptions about computing. Interviews were recorded, transcribed, and coded using Dedoose (a qualitative analysis software program).

The survey [11] captures students' prior experience with computing, and in particular, with programming; their sense of belonging in computing; perceptions of the field of computing; and educational and career aspirations through a mix of openended questions, scale response grid questions (with a mix of 4and 5-point scales), and single choice questions. Students were also asked to assess their anticipated self-efficacy in the course (e.g., keeping up with the work) and their skills and abilities related to success in computing (e.g., problem-solving). Multiple survey items were used to measure each construct. Most items were modified from existing surveys of computing students and of the general freshman population $[3,4,5,19,21]$.

Survey participants were also asked for their gender identification (as an open-ended question), age, and race/ethnicity. They could select all racial/ethnic identities that applied out of a set modified from the HERI CIRP Freshman Survey [15]. For purposes of analysis, we define "minority" as those students reporting at least one non-White race or ethnicity (even if they also selected White). A related variable, "underrepresented minority in computing" (URMC) is based on the National Science Foundation's definition [22] and includes any student who selected Black, Hispanic, American Indian or Pacific Islander as one of their identities.

Key outcome measures are intention to major in a CS/IT field and intention to work in a computing field. We also collected final grades (with student permission) from each course instructor.

\subsection{Scale Construction}

For each group of items, we ran an exploratory factor analysis on the early course data from fall 2017, setting an eigenvalue $\geq 1$ as the inclusion criteria for factors. All analyses were run using SPSS. Multifactor solutions were rotated using a VARIMAX technique. When two-factor solutions resulted, we ran separate factor analyses on the items that loaded together, if the groupings made conceptual sense, excluding items that failed to add explanatory value [10]. For example, programming-related items (e.g., "I enjoy the challenge of programming") loaded together on one factor and items measuring computing impact (e.g., "I would like to find technological solutions to world problems") loaded on a second factor.

We ran confirmatory factor analyses on data from students in spring 2018 courses. Subsequent analyses, reported here, are conducted on the combined fall and spring data, and include rerunning factor analyses to create factor scores.

The following constructs, measured as factor scores, are used in the subsequent analyses:

- Anticipatory course efficacy

- Self-assessment of CS-related skills and abilities

- Interest in programming

- Interest in other aspects of programming

- Perceptions about the field of computing

- $\quad$ Sense of belonging in computing

- Prior programming experience

- Prior experience in other aspects of computing

For a fuller description of these constructs, see [12].

\subsection{Method of Classifying Students}

To understand the types of students enrolling in introductory computing courses at community colleges, and in particular, to explore how introductory students cluster based on key constructs related to success and persistence in computing, we conducted a k-means cluster analysis on the resulting factor scores for all the relevant constructs [2,13]. By using this technique, we hope to challenge the tendency to essentialize differences between women and men (and likewise, among ethnic or racial groups). In our Conclusions, we explore the implications of this approach for pedagogy and the design of retention strategies.

As a clustering method, K-means partitions the data into $\mathrm{k}$ clusters based on minimal Euclidean distances from the assigned cluster's centroid (i.e., the mean distance of all cluster members). In SPSS, the algorithm begins by selecting the first $\mathrm{k}$ cases as starting centroids, assigning the remaining data to clusters based on their distance from each centroid. The centroid for each cluster 
is then recalculated and cases reassigned, as needed, to the nearest centroid. The algorithm terminates when no case is reassigned or when the predetermined number of iterations is reached.

Based on the number of constructs included in the analysis, we estimated that the likely number of groups would be between three and six. Because SPSS selects the first $k$ cases as starting centroids, the solution is sensitive to order. Thus, we calculated solutions for $3<\mathrm{k}<6$, for five random sorts of the data [18]. All eight key constructs--measured as factor scores to standardize the variables--were used in the analysis. We then calculated Cramer's $\mathrm{V}$ for all possible solutions for each set of $\mathrm{k}$ solutions, resulting in five association matrices. High correlations among a particular set of solutions suggests that the solution is stable. Except for random sort 4, the three-centroid solution for all random sorts resulted in Cramer V correlations greater than .938, and the five-centroid solutions resulted in $\mathrm{V}$ correlations $>.845$. Lower correlations among the four-centroid solutions suggest that four categories are not as stable a solution. Since the five-centroid solution provided additional, meaningful differentiation among students over the three-centroid solution, we report on the five-centroid solution for random sort 2. See Figure 1 for the distribution of constructs across student clusters.

\section{Results}

\subsection{Description of the Respondent Sample}

Two hundred and ninety-two students completed at least part of the survey. Overall response rate is difficult to calculate since the survey was administered at slightly different weeks in each course and most faculty members did not have up-to-date enrollment rosters at the time. Figured conservatively, the response rate is within a range of $65-77 \%$. There is, however, some variation on individual items, and thus on the scales.

Students from two colleges account for over $40 \%$ of the respondents $(21.6 \%$ and $19.2 \%)$ since some faculty offered multiple sections both terms, and some faculty did not teach in spring. Almost $60 \%$ of respondents are CS/IT majors, $13 \%$ non-STEM majors and $11 \%$ engineering. CS0 accounted for $45 \%$ of respondents, while 55\% were taking a more programming intensive CS1 course. The majority of students $(+70 \%)$ intend to complete a bachelor's degree. Many $(64 \%)$ were enrolled in the course because it was required, regardless of course level. CS0 students were slightly more likely than CS1 students to be taking the course because they felt it would be "interesting" (46\% vs. $39 \%$ ). (Students could choose more than one reason for taking the course.)

Men comprised $70 \%$ of the resulting sample, with women making up 25\%; five percent declined to provide their gender. White men are the largest demographic group (33\%) followed by men from minority groups historically underrepresented in computing ("URMC" which includes students identifying as Hispanic, African American, or Native/Pacific Islanders). Asian males make up $14 \%$ of the sample. White women and URMC women represent $10 \%$ each, followed by Asian women at $6 \%$. A little over $7 \%$ of the sample declined to provide race/ethnicity data.

\subsection{The Five Student Clusters}

Eight scales were used in the cluster analyses. Because of missing data, the $\mathrm{n}$ for cluster membership is 275 . Table 1 contains the mean factor scores and the range factor scores for each construct.

\begin{tabular}{|l|r|r|r|r|r|r|}
\hline Factors & InAl & ExOn & InOn & ExAl & SemOp & Range \\
\hline Anticipatory Self-efficacy & -0.33 & 0.36 & 0.29 & -0.20 & -0.35 & -.2 .4 to 7.3 \\
\hline Self-assessment & -0.55 & 0.60 & 0.36 & -0.21 & -0.20 & -1.9 to 7.3 \\
\hline Programming Interest & -0.88 & 0.63 & 0.47 & -0.42 & 0.17 & --3.5 to 6.0 \\
\hline Other CS Interests & -0.72 & 0.43 & 0.48 & -0.54 & 0.34 & -2.2 to 5.4 \\
\hline Belonging & -0.63 & 0.53 & 0.44 & -0.50 & 0.02 & -2.3 to 6.4 \\
\hline Perceptions of Computing & -0.38 & 0.15 & 0.41 & -0.54 & 0.00 & -1.9 to 7.6 \\
\hline Prior Programming Exp. & -0.87 & 1.10 & -0.19 & 1.06 & -0.82 & -.95 to 1.4 \\
\hline Other computing Exp. & -0.78 & 1.00 & -0.71 & 0.11 & 0.74 & -1.1 to 1.9 \\
\hline
\end{tabular}

Table 1. Mean factor scores by cluster

Figure 1 is a graphic representation of Table 1, displaying the mean factor score for each cluster on the eight scales used in the factor analysis, arranged from left to right by the cluster with the most students (Inexperienced \& Alienated) to the least (Semiexperienced \& Open).

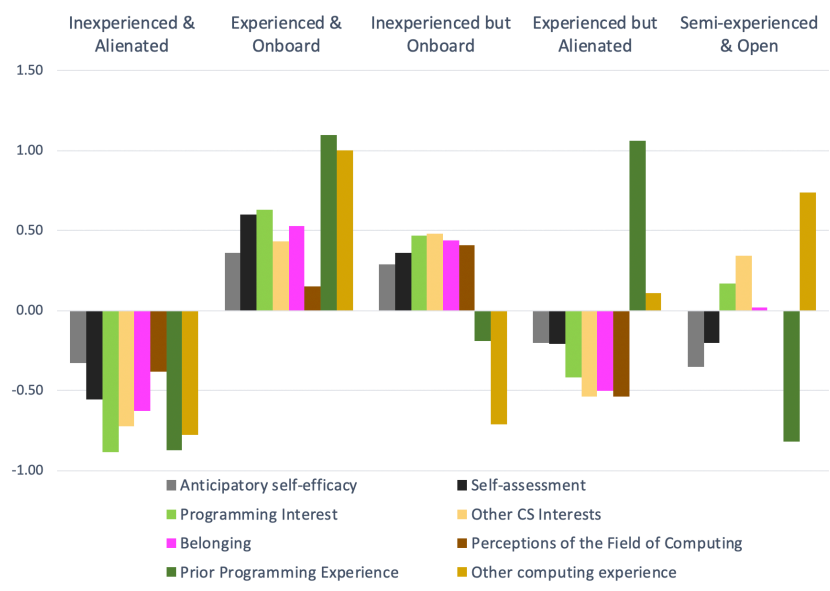

Figure 1. Mean factor scores by cluster

The "Inexperienced \& Alienated" (InAl) students are the most common type (27\%). These students report, on average, the lowest previous experience with and interest in programming and other computing activities, and the lowest sense of belonging in computing. They also report less positive beliefs about the field of computing and, perhaps not unsurprisingly, have the lowest average-but not the lowest-expectation of success in the course. We attribute InAl's lower scores to a lack of experience with and knowledge of the field of computing. They also report the lowest self-assessment on success-related skills and abilities, probably attributable to their lack of experience. It would be wrong, however, to assume that these students are uneducated or generally lacking in confidence.

Profile of an InAl: Victoria, an older student with two master's degrees and ambitions to start a business, comes to CS through an interest in data science. She talks with passion about 
having done "heavy lifting on market research" and "combing big data items" to inform decisions, and yet she remains unsure of her knowledge: "But then again, what do I know about data science and computers?" While InAls may be inexperienced with and unsure about computing, many have experience and interests in other domains that can be used to engage them in computing.

The "Experienced \& Onboard" (ExOn) students are the next most common type, making up $21 \%$ of the sample. These students come into introductory courses with previous experience, confidence in their computing-related skills and abilities, and an expectation of success. They report the highest mean levels of experience with both programming and other computing activities (such as setting up a computer network), and the highest interest in programming and sense of belonging in computing. They score the second highest on socially-relevant computing interests and perceptions of the field.

Profile of an ExOn: Ryan, an 18-year old white man, aims to transfer as quickly as possible to get a bachelor's degree in CS. He took CS in high school, has coding and hardware experience, and loves it: "When I'm doing programming, I don't feel like it's school. . . I can spend like an entire day programming an assignment. That's probably why I did so well last semester." Ryan is intrinsically motivated: "They all weren't the most interesting assignments but they were still gratifying to finish. The coding is interesting." He says he's "pretty good" at math but doesn't "care for it." He has a growth mindset and understands both the difficulty and the time needed to learn CS: "I expected [it] to be difficult, I guess, and I think I did pretty well considering that."

The remainder of the sample is distributed fairly evenly across the other three types.

"The Inexperienced but Onboard" (InOn) (17\%) report on average low levels of experience in programming and other computing activities, but high levels on all other constructs. For example, they score similarly to ExOns in self-assessments of their computing-related skills and abilities, and on expectations of success in the course. In addition, they score slightly higher than ExOns in their interest in computing areas that are more externally focused, such as finding technological solutions to world problems and helping people with computing problems.

Profile of an InOn: George, a 22-year-old Hispanic man, "grew up loving computers" but didn't have opportunities in high school to study CS. "I wish I had more experience ... and I wish I knew that I wanted to get into this earlier so... I could have just been practicing at home." He was enrolled at a 4-year institution as an undeclared major but had to drop out because of health, financial issues, and bad grades ("I kind of fell off"). His father, who works at a tech manufacturing company, got him a job working with robots. That experience changed him: "[I wrote] small scripts [to] see if [the device would] run 100 times without fail. If it does fail, find out why, so I could tell the engineer. I thought that was a lot of fun." He wants to get a BS in computing "because I know that once I get where I want to be... it's going to be somewhere where I can continue to shine."

The "Experienced but Alienated" (ExAl) students (18\%) are almost the mirror image of the InOn Group. These students report mean levels of programming experience similar to the ExOns but differ significantly on almost every other construct. Compared to ExOns, they have lower levels of experience with nonprogramming related computing activities (but still score higher on this construct than the two other groups). However, on all other constructs they look more like the InAls. Because of their high levels of reported programming experience, their lower scores may be due to negative experiences rather than ignorance.

Profile of an ExAl: Olivia, a 20-year-old Latina woman, was a gamer in high school and had loved an app development class she took. She began at university with a CS major, dropped out for personal reasons, but then resumed the CS major at community college. After failing the math prerequisite, she decided to switch to art. She said, "At first it was pretty discouraging because I really wanted to be good at computer science." She worked hard but the inflexibility of programming meant she fell behind. She recalls, "I had really good grades in high school. I thought, 'Oh, this is going to be so easy,' like coding just looked so easy. But it's actually a lot of work." She believed that to be in CS, you needed to be an expert, and she had more expertise in art. To top it off, when she sought help for her CS class, she was ridiculed by the "rude" tutors.

The "Semi-Experienced \& Open" (SemOp) (16\%) report some experience with non-programming related computing activities but one of the lowest mean levels of experience with programming (similar to InAls). They score in the middle of the pack on interest in programming and other computing topics, and on sense of belonging and attitudes toward the field of computing. They tend, as a group, to report the lowest level of anticipated efficacy in the course and one of the lower self assessments of computing-related skills and abilities.

Profile of a SemOp: John is a 19-year-old white male who wants to transfer to get a BS. Currently, he is a Liberal Arts major but wants to pursue a Networking degree. He has no formal CS coursework, but he has taken a computer apart, has done some game modding, and has taught himself some programming. He is taking the introduction course because it is required, but also because he thinks it will be "useful" and "interesting." When asked what might "get in the way" of his success in computing, he said, "Just having to balance all of the other classes and getting past little mental blocks with my coding. Occasionally I have a problem with the conceptual ideas behind the code."

\subsection{Cluster Comparisons: Academic Major and Outcomes}

3.3.1. Distribution of majors across clusters. The majority of students (60\%) in these courses are CS/IT majors and we find CS/IT majors in all clusters. There is, however, a modest but significant relationship between cluster membership and major $(\mathrm{V}=.218, \mathrm{p}<.01)$. Unsurprisingly, CS/IT majors tend to be ExOns $(27 \%)$ or InOns $(22 \%)$. However, CS/IT majors are found in all clusters, including InAls (13\%) and SemOps (19\%). This aligns with previous research showing computing majors are less confident in their abilities than other STEM majors [24]. Not surprisingly, half of the undeclared students are "InAls." A similar pattern is true for Engineering and STEM majors enrolled in these introductory computing courses; $47 \%$ of these majors are InAls. 
3.3.2. Sources of student previous experience in computing. The ExAls are most likely to have had a high school course (64\% compared to $45 \%$ of the ExOns, the one group with higher levels of programming experience) (Cramer's V=.324, $\mathrm{P}<.01)$. There is also a significant relationship between cluster membership and the likelihood of being "self-taught" (Cramer's $\mathrm{V}=.453, \mathrm{p}<.01)$. Only half $(51 \%)$ of the ExAls are self-taught compared to almost $71 \%$ of ExOns and $60 \%$ of SemOps. Interestingly, $45 \%$ of the InOns, who report relatively lower levels of experience, report that they are self-taught and almost $28 \%$ had high school courses. (Students could select more than one source of their computing experience.)

3.3.3. Intent to transfer and reasons for taking the course. We find no significant relationship between intent to transfer and cluster membership. In this sample, most of the students $(80 \%)$ are intending to complete a bachelor's degree. Students were also asked why they were taking the course (e.g., it's required, it's interesting, a friend recommended), selecting as many reasons as applicable. Across the sample, most students were taking an introductory computing course because it was required and/or because they found it "useful." We observed no significant relationship between reasons for taking the course and cluster membership, with one exception. InAls were less likely to be taking the course because it was required. Both InAl and InOn students were the most likely to say they were taking the course because it was "interesting" ( $48 \%$ and $47 \%$, respectively).

3.3.4. Final course grades. While $85 \%$ of students completing the early survey $(n=248)$ gave permission to share their final course grades, we have final course grade data for only $32 \%$ of the sample because some students dropped the course, some did not give permission for grade sharing, and some (6\%) have missing data and cannot be assigned cluster memberships. Because of this, the grade analyses should be interpreted with caution. That said, while the ExOns had the highest mean course GPA and the SemOps (with low self-assessment and low anticipation of success) the lowest, we observed no significant relationship between cluster membership and the likelihood of passing the course (Cramer's $\mathrm{V}=.160$, n.s.) or on final course GPA $(\mathrm{F}(4,186)=.925, \mathrm{p}=.450)$.

3.3.5. Intent to work in computing. Students were asked if they "intend to work in a computing-related field." The majority of students $(68 \%)$ declared that intention, but there was a significant relationship between cluster membership and intention (Cramer's V=.312, $\mathrm{p}<.01$ ). Seventy-nine percent of ExOns said that was their intention and an additional $16 \%$ are already working in a computing field. The vast majority of InOn students (91\%) also said they wanted to work in computing, but only one was already doing so. Interestingly, while they lack confidence in their academic skills, $84 \%$ of SemOps want to work in computing. InAls were the most likely to say they "didn't know" (43\%), followed by ExAls (24\%).

\subsection{Cluster Comparisons: Demographics}

As Figure 2 demonstrates, the clusters do not align neatly with gender and race/ethnicity categories, but there are some notable patterns. Women of all race/ethnicities predominate proportionally in the InAls, the most common student type in our sample. This group also contains a relatively larger proportion of Asian and URMC men, and the lowest proportion of white men.

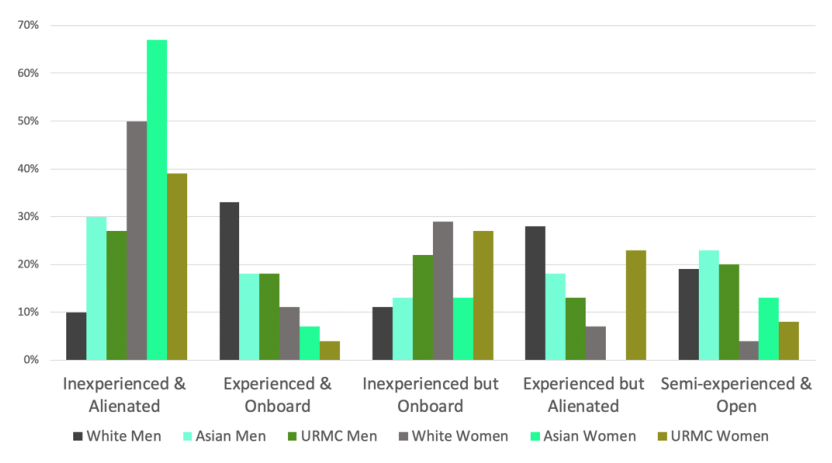

Figure 2. Clusters by intersectional identities

Men predominate proportionally in the ExOn and SemOp clusters, regardless of race/ethnicity. The SemOps have the second highest proportion of Asian men compared to other clusters. The InOn Group has a relatively high proportion of Asian and URMC men and women. The ExAls contain a low proportion of white women, and a higher proportion of the white and Asian men; no Asian women were in the ExAl cluster.

\section{Conclusions}

The K-Means cluster analysis allows us to explore how students can be grouped by key influencers other than race and gender. Rather than asking whether women and men differ on the construct and outcome measures, we developed "types" of students based on those measures. We examined whether women and men are distributed across the "types" of students. Along with helping us challenge essentialist assumptions, it also provides one way to statistically handle intersecting identities, where it matters not only that students are female or male, for instance, but also if they are a female or male of color.

The student clusters illustrate the challenges of teaching introductory computing courses, where student experiences, confidence, and impressions of the field can differ so dramatically [21]. The distribution of race and gender across clusters encourages us to deconstruct stereotypes we may have about who has the potential to be retained in computing. Importantly, the cluster analysis also has the potential to lead to insights into what instructors can do to actively retain students as they grapple with the content of a CS0 or CS1 class in their early years of postsecondary education. To this end, we offer some suggestions for ways to teach and retain the types that emerged from this sample.

The InAl Group: Because these students have the lowest interest and experience levels, and lower expectations for success, they may be most "susceptible" to being surprised by a positive experience in an introductory CS course. Remember: They were one of two groups most likely to say they were in the course because it was "interesting." Recognizing that a lack of experience with computing may lead to an expectation of failure, instructors 
can: (1) acknowledge the experience gap and scaffold instruction to bridge it, (2) provide explicit encouragement to individual students, and (3) connect computing content to student interests and their areas of existing expertise [14].

The ExOn Group: These students have both experience and interest, which brings a high expectation for succeeding in the class. ExOns are likely the easiest group to teach. However, the challenge is making sure they have good study and coding habits, and that in their confidence they don't overshadow, dominate, or intimidate other students.

The ExAl Group: While sharing similar experience levels with ExOns, ExAl students likely have had negative experiences with computing, whether before or during college. Thus, they need to be reinspired. Linking class activities and skills to realworld applications and fostering positive student community may help to retain these experienced students in the major.

The InOn Group: While they lack experience, InOn students are nearly as enthusiastic as ExOns, and in this sample, they are the most demographically diverse group. They need encouragement as they build the skills to match their interest. Instructors need to be cautious: Research suggests that computing interventions can sometimes dampen inexperienced students' interest in computing because they may not realize how hard computing can be, how exacting programming is, or how much time the class will take [17]. Thus, these students need scaffolding as well as a reason to stick it out. Even with confidence in their academic skills, the InOn group still may be vulnerable to intimidation by students with more experience.

The SemOp Group: These students have some general computing experiences (but not programming) and could skew positive or negative on their attitudes toward computing and toward their potential success in the course. As their name suggests ("Open"), they need direct encouragement to keep them motivated and to build their confidence. They scored low on selfassessment of computing abilities so will likely benefit from scaffolding.

In closing, we encourage faculty to bear in mind two student's perspectives on these introductory courses to remind ourselves how important the first courses are to recruitment and retention:

If we're basing everything off this one class, we may see tech as this boring, mundane thing where we're just gonna sit at a desk typing up...programs, which is horribly dull.

We need labs which are more relatable to students' everyday life...a little bit more fun for the students, to make them see, 'Oh! I actually like this! I don't know what I am doing but I like what the concept is!'

\section{Limitations and Future Research}

We want to note a few important limitations of our research as well as our plans for future research. First, the finding that the $\mathrm{CS} / \mathrm{IT}$ major is distributed across clusters may be an artifact of the way students choose a major at community college and may not replicate at 4-year institutions. Second, it is notable that there wasn't a stronger association between cluster type and final grade, but students that dropped before final grades are not included in the sample, so their absence may well be suppressing an effect. However, while the sample size is relatively limited-both in terms of size and scope (all from community colleges)-the study is strengthened by the variety of institutions and backgrounds of students included in the dataset.

Because of the preliminary nature of these findings, the final version of the survey instrument and the cluster analytic technique are not ready for wide dissemination and use. In future work, we intend to validate the technique on a larger and differently constructed sample, including 4-year CS0 and CS1 students to account for structural differences between 4-year and 2-year institutions and potential differences between the kinds of students each institution type attracts. Once we have refined the statistical approaches and validated the student types, we will share our data collection and analytic techniques with the computing education community, where it could be helpful in two ways: (1) as a powerful theoretical frame for future research on pedagogical innovation informed by research-based constructs rather than a priori demographics, and (2) as support for CS0 and CS1 faculty by providing a helpful snapshot of the types of students they may encounter in their courses and insight into how to better teach and retain those students.

\section{ACKNOWLEDGMENTS}

We want to thank the participating faculty, who must remain unidentified, for their invaluable contributions to data collection and to our understanding of the community college context. We also thank our project Advisory Board-Cheryl Calhoun, Sarah Hug, Pat Morreale, Lisa Sandoval, Khallai Taylor, and Melanie Williamson-for their keen insights. Jamie Huber Ward contributed significantly to the professional development which is core to this project. Finally, we thank the students who participated in surveys and interviews. This research is supported by the National Science Foundation under Grant No. 1525652. Any opinions, findings, and conclusions expressed in this paper are those of the authors and do not necessarily reflect the views of the NSF.

\section{REFERENCES}

[1] Joanne M. Badagliacco, 1990. Gender and race differences in computing attitudes and experience. Social Science Computer Review 8, 1, (April 1990), 42-63. DOI: 10.1177/089443939000800105.

[2] Mark S. Aldenderfer and Roger K. Blashfield. 1984. Cluster Analysis. Sage, Beverly Hills, CA

[3] Center for Community College Student Engagement. 2015. Community College Survey of Student Engagement (CCSSE). University of Texas, Austin, TX. Retrieved from http://www.ccsse.org/.

[4] Center for Community College Student Engagement. 2015. Survey of Entering Student Engagement (SENSE). University of Texas, Austin, TX. Retrieved from http://www.ccsse.org/sense/.

[5] Center for Postsecondary Research. 2013. National Survey of Student Engagement. Indiana University School of Education, Bloomington, IN. Retrieved from http://nsse.indiana.edu/html/survey_instruments.cfm

[6] Computing Research Association. 2018. The Data Buddies Project. Retrieved from https://cra.org/cerp/data-buddies/ 
[7] Christianne Corbett and Catherine Hill. 2015. Solving the Equation: The Variables for Women's Success in Engineering and Computing. American Association of University Women, Washington, DC.

[8] Peter M. Crosta. 2014. Intensity and attachment: How the chaotic enrollment patterns of community college students relate to educational outcomes. Community College Review 42, 2 (February 2014), 118 - 142 https://doi.org/10.1177/0091552113518233

[9] Jill Denner, Linda Werner, Lisa O 'Connor, and Jill Glassman. 2014 Community college men and women: A test of three widely held beliefs about who pursues computer science. Community College Review 42, 4 (May 2014), 342-362.

[10] Christine Distefano, Min Zhu, and Diana Mîndrilă. 2009. Understanding and using factor scores: Considerations for the applied researcher. In Practical Assessment, Research \& Evaluation 14, 20 (Oct. 2009), 1-11.

[11] Wendy M. DuBow and Beth A. Quinn. EngageIT Early Course Survey. Retrieved from https://inyurl.com/Quinn-DubowStudentSurvey.

[12] Wendy M. DuBow and Beth A. Quinn. EngageIT Early Course Survey Scales. Retrieved from https://tinyurl.com/EngageIT-scales.

[13] John Fiedler and John J. McDonald. 1993. Market Figmentation: Clustering on factor scores versus individual variables. AMA Adv. Res. Tech. Forum, 1-14, 1993. Retrieved from https://tinyurl.com/FielderMcDonald1993

[14] Andrea Forte and Mark Guzdial. 2005. Motivation and nonmajors in computer science: Identifying discrete audiences for introductory courses. IEEE Transactions on Education 48, 2 (May 2005), 248-253. DOI: 10.1109/TE.2004.842924

[15] Higher Education Research Institute. 2015. CIRP Freshman Survey 2015. Retrieved from https://heri.ucla.edu/cirp-freshman-survey.

[16] Catherine Hill, Christianne Corbett, and Andresse St Rose. 2010. Why So Few? Women in Science, Technology, Engineering, and Mathematics American Association of University Women, Washington, DC. Retrieved from https://www.aauw.org/research/why-so-few.

[17] Yingdan Huang, Jane Meyers, Wendy M. DuBow, Zhen Wu and Michael Eisenberg. 2012. Programming plush toys as an introduction to computer science: The (fraught) question of motivation. In Ubiquitous and Mobile
Informal and Formal Learning in the Digital Age. D.G. Sampson, P. Isaias, D. Ifenthaler, J.M. Spector (Eds.) New York, Springer. ISBN 978-1-46143328-6

[18] IBM, 2016. K-Means Cluster (QUICK CLUSTER) Results Sensitive to Case Order. Retrieved August 15, 2018 from http://www01.ibm.com/support/docview.wss?uid=swg21476878.

[19] Kathleen J. Lehman, Linda J. Sax, and Hilary B. Zimmerman. 2017. Women planning to major in computer science: Who are they and what makes them unique? Computer Science Education 26, 4 (Jan 2017), 277298.

[20] Jane Margolis and Allan Fisher. 2002. Unlocking the Clubhouse: Women in Computing. The MIT Press, Cambridge, MA.

[21] National Center for Women \& Information Technology. 2015. Survey-in a-Box: Student Experience of the Major. Retrieved from https://www.ncwit.org/resources/survey-box-student-experiencemajor- 0 .

[22] National Science Foundation. 2012. CISE Strategic Plan for Broadening Participation. National Science Foundation, Alexandria, VA. Retrieved from https://www.nsf.gov/cise/oad/cise_bp.jsp.

[23] Beth A. Quinn, Wendy M. DuBow, and Jamie Huber-Ward. 2018 Broadening participation in computing via professional development for community college CS/IT faculty. In Proceedings of the 49th ACM Technical Symposium on Computer Science Education (SIGCSE '18). ACM Press, New York, NY, 789-793. DOI: https://doi.org/10.1145/3159450.3159546

[24] Elaine Seymour and Nancy M. Hewitt. 1997. Talking About Leaving: Why Undergraduates Leave the Sciences. Westview Press, Boulder, CO.

[25] Henry M. Walker. 2017. Retention of students in introductory computing courses: Curricular Issues and Approaches. ACM Inroads 8, 4 (Oct. 2017), 12-12. DOI: $10.1145 / 3151936$

[26] Susan Wiedenbeck. 2005. Factors affecting the success of non-majors in learning to program. In Proceedings of the First International Workshop on Computing Education Research (ICER '05). ACM, New York, NY, USA, 1324. DOI: $10.1145 / 1089786.1089788$. 